\title{
The inflammatory caspases: guardians against infections and sepsis
}

\author{
AM Scott ${ }^{1}$ and M Saleh ${ }^{*, 1,2}$
}

Innate immunity is the primary host defense against invading microorganisms. Pathogen recognition, mediated through an elaborate 'microbial sensing' system comprising the Toll-like and Nod-like receptor families results in the activation of caspase1 , which is a prerequisite for pathogen clearance. Tight regulation of caspase-1 is necessary to control the magnitude of the innate immune response and protect the organism from possible damaging effects such as sepsis. Recent findings from population studies and animal models of infectious diseases and sepsis have uncovered a role for full-length caspase-12 in blocking the inflammatory response initiated by caspase-1, thus predisposing the organism to severe sepsis and sepsis-related lethality. In this review, we re-examine the relationship among the Group I caspases, their known substrates and their proposed role in apoptosis. We further discuss their function in inflammation and bacterial clearance, with an emphasis on their regulatory mechanisms during the innate immune response.

Cell Death and Differentiation (2007) 14, 23-31. doi:10.1038/sj.cdd.4402026; published online 15 September 2006

\section{The Innate Immune System in the Sepsis Response}

The enigma of sepsis. In 1972, Lewis Thomas noted that it is the response of the individual, rather than the invading microorganism, that constitutes the disease. ${ }^{1}$ Sepsis has been broadly defined as the host's systemic response to an infection, but generally required the confirmation of a bacterial infection and the diagnosis of any two clinical signs of the Systemic Inflammatory Response Syndrome (SIRS): changes in number and immaturity of white blood cells, in body temperature, heart or respiratory rates. This definition of sepsis, however, was problematic since staging of the clinical severity of the disease was difficult to perform. In 1992, the terms 'severe sepsis' and 'septic shock' were coined. ${ }^{2}$ While septic shock is a rapid, highly lethal syndrome occuring 24$48 \mathrm{~h}$ after onset, severe sepsis is a slower syndrome that occurs 7-14 days after onset, and is accompanied by multiple organ dysfunction and a mortality rate of $30-70 \%$ (Box 1 ). A more recently defined staging system, $P I R O,{ }^{3}$ takes into account the predisposition, the insult, the response of the host system and the organ dysfunction, and is expected to improve the design and outcome of clinical trials.

\section{The Cytokine Code in Sepsis}

Inflammatory cytokines are essential mediators of the innate immune response. While it is believed that excessive cytokine levels set the stage for capillary leakage, tissue injury and organ failure, it is also well documented that the innate immune system in septic patients is suppressed and unable to properly clear pathogens. ${ }^{4}$ To date, clinical trials based on anti-inflammatory strategies such as corticosteroids, antiendotoxin antibodies and TNF $\alpha$ and IL-1 $\beta$-receptor antagonists have nearly all failed. ${ }^{5}$

Experts agree that grouping patients with heterogeneous conditions under the same diagnosis of 'severe sepsis' has led to a lack of significance and failure to reproduce results in clinical trials. Additional problems included incorrect assumptions and incorrect sepsis animal models. It was assumed, for instance, that during sepsis elevated levels of LPS, the main component of Gram-negative bacterial cell walls, were shed in the circulation. This led to injection of lethal doses of LPS in rodents as a model of sepsis. We now know that this is an endotoxic shock model and does not represent what happens in sepsis, where LPS levels are almost 200 -fold lower than those found in response to LPS overdose. ${ }^{6}$ As a result, human trials aimed at eliminating LPS, using either hemofiltration or anti-endotoxin antibodies were carried out, but failed to treat sepsis (Box 1). ${ }^{7}$ In response to LPS overdose, rodents produce exponentially higher levels of $\mathrm{TNF} \alpha$ and IL-1 $\beta$ than those found in human sepsis, and this 'cytokine storm' causes endotoxic shock. Blocking the effects of $\mathrm{TNF} \alpha$ and IL-1 $\beta$ production using receptor antagonists has also proved unsuccessful in treating sepsis.

\footnotetext{
${ }^{1}$ Department of Biochemistry, McGill University, Montreal, Canada H3G $1 \mathrm{Y} 6$ and ${ }^{2}$ Department of Medicine, McGill University, Montreal, Canada H3A 1A1 ${ }^{*}$ Corresponding author: M Saleh, Department of Medicine, McGill University, Montreal, Canada H3A 1A1. Tel: +1514 9341934 ext 34416 ;

Fax: + 1514843 1686; E-mail: maya.saleh@mcgill.ca

Keywords: apoptosis; caspase-12; inflammatory caspases; pathogen sensing and innate immunity; sepsis and infectious diseases

Abbreviations: SIRS, Systemic Inflammatory Response syndrom; PIRO, predisposition, insult^response of the host system and organ dysfunction; TNF, Tumor necrosis factor; IL-1, Interleukin-1; IL-1ra, Interleukin-1 receptor antagonist; IL-18, Interleukin-18;; IGIF, Interferon gamma inducing factor; IFN, Interferon; LPS, Lipopolysaccharide; TLR, Toll-like receptor; CARD, Caspase recruitment domain; ICE, Interleukin-1 beta converting enzyme; MSU, Monosodium urate; CPPD, Calcium pyrophosphate dihydrate; CINCA, Chronic Infantile Neurologic Cutaneous and Articular syndrome; ER, Endoplasmic reticulum; CrmA, cytokine response modifier A; SNP, Single nucleotide polymorphism

Received 05.6.06; revised 12.7.06; accepted 21.7.06; Edited by S Kumar; published online 15.9.06
} 


\section{A Health and Financial Burden}

- Sepsis is the second most common cause of death in intensive care units

- 750,000 cases of severe sepsis are reported per year in the US, with mortality rates higher than $50 \%$

- Treating sepsis costs US approximately $\$ 17$ billion annually

\section{Clinical Manifestations}

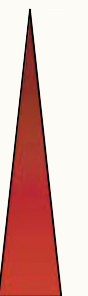

Infection - Invasion of a host sterile tissue by a microorganism

Sepsis $\quad-$ Systemic inflammatory response to an infection with 2 or more criteria of SIRS (e.g. changes in body temperature, tachycardia, tachypnea, changes in number or immaturity of WBCs)

Severe Sepsis - Sepsis complicated by organ dysfunction

Septic shock - Hypotension (despite adequate fluid resuscitation), tissue oxygen debt and multiple organ dysfunction syndrome (MODS)

\section{Clinical Trials and Outcomes}

- $\quad$ LPS removal using hemofiltration or anti-endotoxin antibodies has failed

- Anti-inflammatory strategies using corticosteroids, TNF $\alpha$ and IL- $1 \beta$-receptor antagonists have also failed to treat sepsis

- Anti-immunosuppressive approaches using INF $\gamma$ have shown therapeutic promise

In contrast to immunosuppressive or anti-inflammatory approaches, stimulation of the immune system using antiimmunosuppressive strategies, such as recombinant IFN $\gamma$ or caspase inhibitors, has proven beneficial in experimental models of sepsis. ${ }^{8-10}$ Our recently published results describe an association between severe sepsis and the full-length variant of Caspase-12 (Csp-12L). ${ }^{11,12} \mathrm{Csp}-12 \mathrm{~L}$ appears to dampen the inflammatory response, suggesting that a suppressed immune system would render an individual more prone to infections and more susceptible to sepsis. This data is, therefore, in disagreement with the notion that individuals with lower cytokines are expected to suffer a less severe form of sepsis. Although inflammatory cytokines are harmful when produced in excess, they are necessary for an initial attempt at bacterial clearance by the innate immune system. $\mathrm{C} 3 \mathrm{H} / \mathrm{HeJ}$ mice deficient in TLR4, which detects LPS and initiates a signaling pathway to activate cytokine production, are highly resistant to this bacterial product but are susceptible to bacterial infection. ${ }^{13,14}$ Similarly, humans administered with anti-TNF $\alpha$ therapy, or deficient in TLR $4^{15}$ are also more prone to infections.

\section{Part I - The Inflammatory Caspases: Relationship, Regulation and Substrates}

Before discussing the role of the inflammatory caspases in sepsis, it is useful to briefly describe their relationship, substrates and regulatory mechanisms. Caspases are cysteinyl aspartate-specific proteinases known for their roles in apoptosis and cytokine maturation. They are classified into two subfamilies according to their structure, function and substrate specificity as either the inflammatory (Group I) or apoptotic (Groups II and III) caspases. ${ }^{16}$

Group-I caspases include caspase-1 (ICE; Interleukin-1 $\beta$ Converting Enzyme), $-4,-5$ and -12 . Caspase -5 is absent in mice, and likely arose in higher species from tandem gene duplication of caspase-4. Mouse caspase-11 appears to be the ortholog of human caspase-4. The inflammatory caspases are found clustered together on human chromosome 11q22.2-q22.3 and on a syntenic region of mouse chromosome 9A1. They are arranged from telomere to centromere as caspases-1, $-5,-4$ and -12 in humans and as caspases-1, -11 and -12 in mice (Figure 1a). Caspase- 1 is also found in close proximity to two genes encoding CARD-only proteins: ICEBERG and COP (or pseudo-ICE). The close proximity of inflammatory caspase genes, along with their exon-intron structure supports the hypothesis that they originated from the same ancestral gene(s).

Expression patterns and gene regulation. Various cellular mechanisms ensure that the inflammatory caspases are kept under control. Alternative splicing, tissue-specific distribution and gene induction by inflammatory stimuli add to the complexity of their regulation. With the exception of caspase-4, the inflammatory caspases are expressed at low levels in most tissues, but are constitutively expressed at high levels in monocytes, macrophages and to a lesser extent in neutrophils. ${ }^{17}$ Conversely, caspase- 4 is normally present at high levels in most tissues. An important characteristic of its gene regulation is its robust induction by $\operatorname{IFN} \gamma .{ }^{18,19}$ 
a
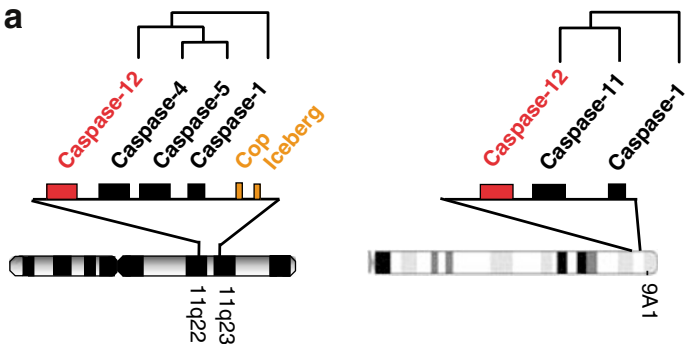

b

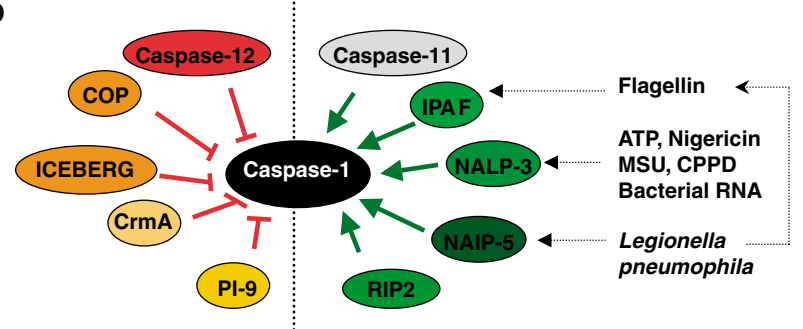

Figure 1 Phylogenetic relationship among the inflammatory caspases and modulators of caspase-1 activity. (a) Phylogenetic relationship and chromosomal localization. In humans, the group I caspases are found arranged on chromosome 11q22-23 from telomere to centromere as caspases-1, $-4,-5$, and -12. In mice, the inflammatory caspase locus is on chromosome $9 \mathrm{~A} 1$ and the order is caspases-1, -11 , and -12 . The absence of caspases- 4 and -5 in mice, and their high degree of homology to caspase- 11 suggests that they may have arisen in higher primates due to gene duplication of caspase-11. COP and Iceberg, encoding two CARD-only proteins are found in the human but not the murine inflammatory caspase locus. (b) Activators and inhibitors of caspase-1. Several factors have been found which modulate the activity of caspase-1. Activators are largely comprised of inflammasome scaffolding proteins of the NOD-like receptor (NLR) family such as NALP-3, NAIP-5 and IPAF. In resposne to bacterial products or changes in intracellular $\mathrm{pH}$, these scaffolding molecules recruit caspase-1 into a macromolecular complex and result in its activation. In addition to NLRs, the CARDcontaining proteins caspase-11 and RIP2 have also been shown to be required for caspase- 1 activation. Inhibitors of caspase- 1 include Crm A, PI-9 and the two CARD-only proteins, COP and ICEBERG. More recently, caspase-12 was identified as an additional potent natural inhibitor of caspase-1

Caspase-12 message can be found in almost all tissues, with its highest expression observed in the lung, stomach and small intestine. ${ }^{20}$ However, constitutive protein expression is restricted to skeletal muscle, heart, brain, liver, eye, testis and to a much lesser extent in the lymph nodes, thymus and spleen. ${ }^{21}$ Caspase-12 is also highly induced by IFN $\gamma$ and bacterial products in various cell types including splenocytes and macrophages. ${ }^{12}$ LPS has also been demonstrated to be an inducer of most inflammatory caspases. ${ }^{22-24}$

Activators and inhibitors of the inflammatory caspases. Our knowledge concerning the mechanisms of caspase- 1 activation has increased tremendously in the last few years. However, we still lack information on the regulatory events leading to the activation of caspases-4, $-5,-11$ and -12 . For some time now, we have known that bacterial products, in conjunction with ATP or Nigericin (which disrupt the intracellular ionic milieu and result in cytosol acidification), lead to caspase-1 activation. ${ }^{25,26}$ However, it was not clear how these signals converged to activate caspase-1. Greater insight into the mechanisms of caspase- 1 activation came with the characterization of the inflammasome, a macromolecular complex required for caspase-1 activation (reviewed by Fabio Martinon and Jurg Tschopp). Although ligands for the inflammasome remain elusive, recent studies investigating the NALP-3 inflammasome showed that ATP, the toxin Nigericin, ${ }^{27}$ bacterial RNA, ${ }^{28}$ gout-associated monosodium urate (MSU) and calcium pyrophosphate dihydrate (CPPD) crystals $^{29}$ induce NALP-3 inflammasome activity (Figure 1b). Similarly, flagellin from both Salmonella and Legionella has been reported to activate the IPAF inflammasome. ${ }^{30-33}$ Although the characteristics of an inflammasome ligand are not known, which inflammasome is assembled in response to such a specific ligand is even more elusive. It is clear from both the NALP-3-deficient mice ${ }^{27-29}$ and from patients with the autoinflammatory disorders Muckle Wells syndrome, Familial Cold Urticaria and Chronic Infantile Neurologic Cutaneous and Articular syndrome (CINCA) that other NALPs cannot compensate for the loss of NALP $-3 .^{34}$ Similarly, NAIP-5 is the specific molecule engaged in response to Legionella pneumophila, ${ }^{35}$ further suggesting that inflammasomes are highly specialized structures activated in a non-redundant fashion by highly specific stimuli.

In most instances, the activation of caspase-1 was assessed by monitoring $\mathrm{IL}-1 \beta$ secretion and caspase- 1 processing. The lack of substrates for caspases- 4 and -5 led researchers to examine the processing of these caspases as a read-out of their activation. Caspase- 5 has been shown to be processed in the NALP-1 inflammasome, ${ }^{36}$ however, we do not know whether the cleaved caspase-5 is active, nor whether it was processed by caspase- 1 or by a caspase- 5 autocleavage event. Caspase-4, on the other hand, has been suggested to be activated by endoplasmic reticulum (ER) stress and to induce apoptosis in response to this stress, as well as in response to the neurotoxic peptide amyloid $\beta-\mathrm{a}$ fibril associated with localized amyloidosis in Alzheimer's disease. ${ }^{37}$ Although these findings are interesting, they are currently controversial, as reported in reference. ${ }^{38}$

In addition to the activators of caspase-1, we know of different caspase-1 inhibitors (Figure 1b). A first look at caspase-1 inhibition came from studies using the viral protein Cytokine response modifier (CrmA), which was known to dampen the cytokine response. ${ }^{39} \mathrm{CrmA}$ was shown to inhibit caspase-1 mediated cleavage of pro-IL-1 $\beta$. Another proposed caspase-1 inhibitor, serpin PI-9, is constitutively expressed within human vascular smooth muscle cells, and was shown to be responsible for caspase-1 inhibition and the resulting loss of pro-IL-1 $\beta$ and pro-IL-18 processing. ${ }^{40}$ In addition to CrmA and PI-9, caspase-1 enzymatic activity has been shown to be inhibited by the CARD-only proteins ICEBERG and COP,${ }^{41-43}$ which physically interact with caspase-1. It is, therefore, conceivable that they inhibit caspase- 1 by acting as dominant negative regulators interfering with the recruitment of caspase- 1 to an activating inflammasome. More recently, we have shown that caspase-12 blocks caspase- 1 catalysis as we describe in more detail below. ${ }^{12}$

Substrates. With the exception of caspase-12, caspases-1, $-4,-5$ and -11 share a preference for the substrate sequence Trp-Glu-His-Asp (WEHD). In rodents, caspase-12 recognizes and cleaves itself at the $A T A D^{319}$ site 
(manuscript in preparation) but does not cleave any of the caspase tetrapeptide fluoregenic peptides or any cellular protein examined to date. Very little is known about the physiological substrates of the inflammatory caspases. Caspase-1 is known to cleave pro-IL- $1 \beta,{ }^{44}$ pro-IL-18, ${ }^{45}$ the related IL-1 family member IL-1F7b (also known as IL$1 \mathrm{H} 4^{46}$ ), and IL-33. ${ }^{47}$ In vitro, caspase- 1 has also been shown to process actin, ${ }^{48}$ the kinase PITSLRE ${ }^{49}$ and parkin. ${ }^{50}$ However, the relevance of this in the inflammatory response and programmed cell death remains unclear. Caspase- 4 has been shown to process pro-IL-18 and IL-1F7b inefficiently, ${ }^{46}$ but has been suggested to cleave caspase- 3 into its active form. ${ }^{51}$ Similarly, caspase-5 is also reported to cleave caspase $-3^{52}$ and process the transcription factor Max in vitro. $^{53}$ The only substrates reported for caspase-11 are caspases $-1^{54}$ and $-3 .{ }^{55}$

\section{Part II - The Inflammatory Caspases in Innate Immunity and Inflammatory Disorders}

Although we know of few substrates cleaved by the inflammatory caspases, their role in modulating the IL-1 $\beta$ and IL-18 pathways render them important players in the host response to pathogenic invasion. Caspase-1 deficient mice are more susceptible to bacterial infections such as Escherichia coli, Listeria, Francisella and Salmonella than their wild-type counterparts (Table 1). ${ }^{56-59}$ Similarly, A/J mice with polymorphisms in the caspase-1 activating protein NAIP5 are more susceptible to infection by Legionella pneumophila as compared to C57BL/6 mice in which caspase-1 activation is intact. ${ }^{35}$ Caspase-11 has been suggested to act in vivo as an essential activator of caspase- 1 and as its obligate partner. In support of this, caspase-11 deficient mice were shown to be incapable of producing IL-1 $\beta$ and IL-18 in response to LPS stimulation. ${ }^{60}$ Nonetheless, it seems that the requirement of caspase-11 for caspase-1 activation is not absolute and is restricted to certain stimuli, as caspase-1 could be normally activated in the absence of caspase-11 in response to Listeria infection (Table 1). ${ }^{61}$ This is consistent with observations in human macrophages, where caspase-5, a caspase-11related protein, is only recruited to the NALP1 inflammasome and not other caspase-1 activating complexes. In contrast to caspase-11, caspase-12 inhibits the activity of caspase- 1 . Consistently, we have found that caspase-12 deficient mice are more resistant to bacterial infections and sepsis than wildtype mice (Table 1). ${ }^{12}$ Therefore, it appears that caspase- 1 is the executioner caspase in inflammation and that caspases-
11 and -12 are regulators of its activity. While caspase- 1 is essential in the host defense against microorganisms, its activity needs to remain under stringent control. Excessive caspase-1 activation results in endotoxic shock. This has been demonstrated in LPS overdose animal models where both mice deficient in caspases- 1 and -11 were resistant to endotoxic shock (Table 1). ${ }^{25,26,60}$ Another instance where excessive caspase-1 activity is deleterious is evident in human patients with the auto-inflammatory disorders Muckle Wells syndrome, Familial Cold Urticaria and CINCA. These patients suffer from uncontrolled caspase-1 activation due to mutations in the gene for the caspase- 1 activating protein cryopyrin/NALP-3. ${ }^{34}$ Natural caspase-1 inhibitors are therefore important in modulating its response. The inhibitory function of caspase-12 on caspase-1 appears to be a dominant effect and detrimental for the individual as it leads to increased susceptibility to infections and severe sepsis. ${ }^{11,12}$

Caspase-12: a deleterious protein. Polymorphisms in human caspase-12 have been found which drastically alter its function. Most notable is the substitution of a thymidine at position 125 for a cytosine. This single nucleotide polymorphism (SNP), which occurs in exon 4, changes the codon from a stop to an arginine residue, thus resulting in read-through and synthesis of a full length protein (Figure 2a). ${ }^{20}$ Most individuals express the truncated form of caspase-12. Only in about $20 \%$ of individuals of African descent is the full length variant expressed, and the consequences can be severe. ${ }^{11}$ Individuals expressing the full-length variant have a dampened inflammatory response to endotoxins, and have an increased risk of developing severe sepsis. ${ }^{11}$ Analysis of population genetics suggests that the truncated form of caspase-12 arose in Africa approximately 100000 years ago. Following its migration out of Africa, a positive selection pressure is believed to have driven it to near fixation. ${ }^{62}$ This selection pressure is believed to be largely due to rising infectious diseases and sepsis in Europe and Asia, thus favoring the truncated caspase-12 variant and sepsis resistance (Figure 2b). ${ }^{62}$

Like the human full-length variant of caspase-12, murine caspase-12 also appears to abrogate the inflammatory response. Recently, we reported that caspase-12 deficient mice are more resistant to sepsis, and are able to clear bacterial pathogens more efficiently than wild-type mice. This may largely be due to the inhibitory effect caspase-12 has on

Table 1 The role of the inflammatory caspases in the regulation of IL-1 $\beta$ and IL-18 production impacts on bacterial clearance and sepsis resistance

\begin{tabular}{llll}
\hline Mouse strain & LPS overdose model & Peritonitis-induced sepsis models & Listeria infection model - bacterial clearance \\
\hline Caspase-1 $1^{-/}$ & Resistant & ND & Reduced \\
Caspase-11 $11^{--}$ & Resistant & ND & Similar to wild-type \\
Caspase-12 & Susceptible & Resistant & Enhanced \\
\hline
\end{tabular}

The activity of caspase- 1 is necessary for bacterial clearance and sepsis resistance: Caspase- 1 deficient mice are susceptible to bacterial infections, while caspase12 deficient mice, in which caspase-1 is de-repressed, are resistant to both infections and sepsis. Excessive caspase-1 activity however leads to endotoxic shock. Mice deficient in either caspases-1 or -11 are resistant to endotoxic shock induced by LPS overdose, while caspase-12 deficient mice are as susceptible as wild-type mice to LPS overdose. Caspase-11 seems to be required for the activation of caspase-1 in response to LPS but is dispensable during Listeria infection. ND: not determined 

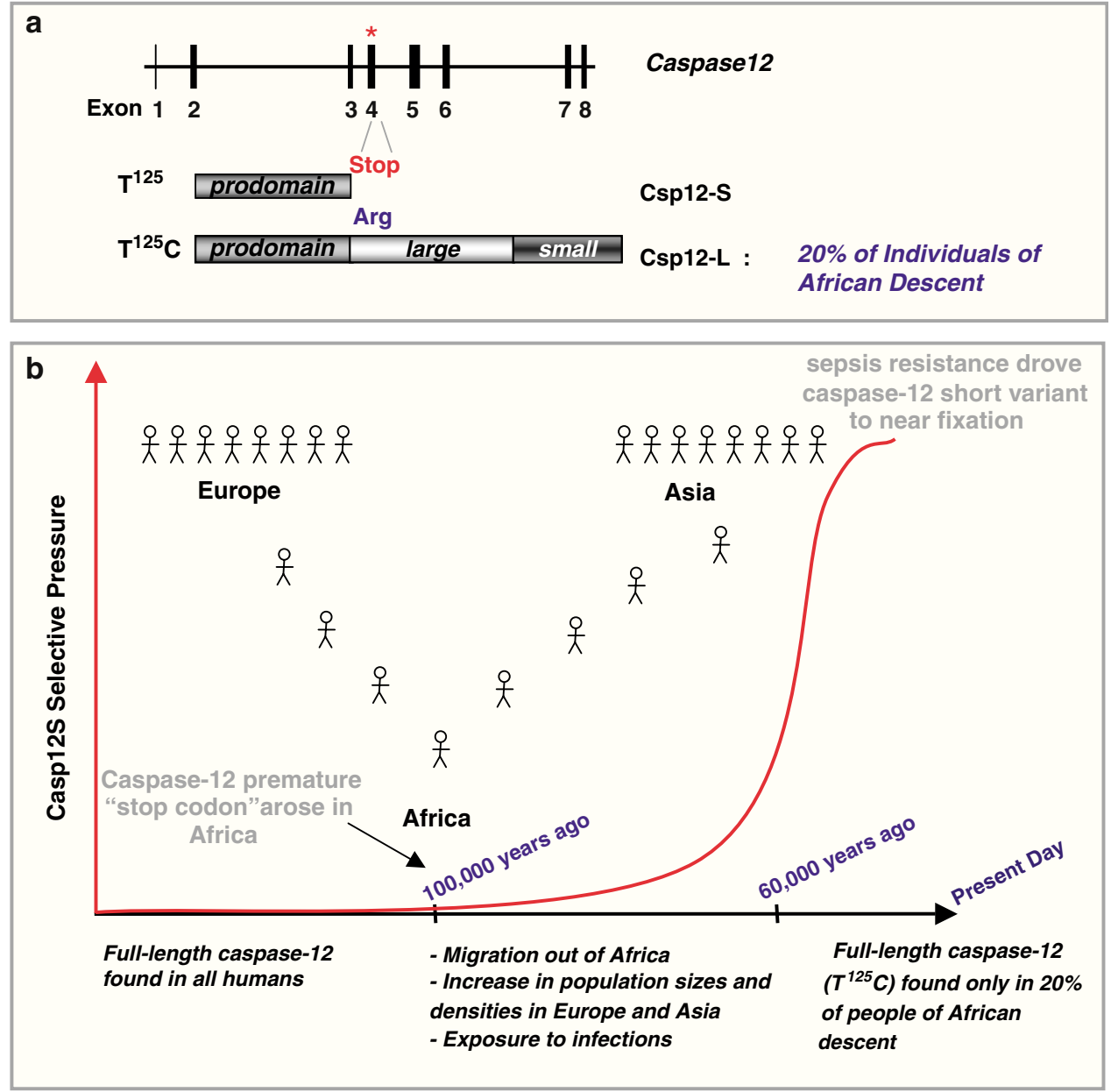

Figure 2 The human caspase-12 polymorphism and sepsis resistance. (a) The $T^{125} \mathrm{C}$ SNP, which resides in exon 4 of human caspase-12, encodes a premature 'stop' codon when $\mathrm{T}$ is present at nucleotide position 125 and an arginine when $\mathrm{C}$ is present at this position. The presence of the premature stop codon results in the synthesis of a truncated prodomain-only protein, Csp-12S, while the arginine at this position allows for a readthrough and the production of a full-length protein, Csp12L. (b) The importance of this SNP in sepsis resistance is paramount. Individuals expressing the full-length caspase-12 variant are more susceptible to bacterial infections and sepsis than those expressing the truncated form. It is postulated that the truncated variant arose in Africa nearly 100000 years ago. It was not until the migration out of Africa to Europe and Asia that a selective pressure favoring this variant grew. An increased incidence of infection, along with higher population densities and sizes in Europe and Asia are believed to have constituted a selective pressure which favored the truncated variant, and hence, sepsis resistance

caspase-1 (Figure 3). This hypothesis is supported by the observation that caspase-12-deficient splenocytes secrete higher levels of mature IL-1 $\beta$ and IL-18, compared to wild-type splenocytes, in response to various stimuli. Interestingly, the enzymatic function of caspase-12 is not required for its inhibitory effect on caspase-1. This was determined in studies employing caspase-12 with a catalytic cysteine-to-alanine mutation, which still blocked caspase- 1 catalysis and IL-1 $\beta$ processing. $^{12}$

In light of these findings, caspase-12 could serve as a therapeutic target for the treatment of sepsis. By the same token, activators of caspase- 1 should result in the same outcome, and may also hold therapeutic value. Alternatively, therapy involving recombinant mature IL-18 (a caspase-1 substrate also known as IGIF or IFN $\gamma$-Inducing Factor) could also prove effective in treating sepsis, as treatment with recombinant IFN $\gamma$ seems to ameliorate the sepsis phenotype in humans. ${ }^{8,10}$

\section{Part III - The Inflammatory Caspases in Apoptosis}

It is unclear whether or not the inflammatory caspases play a direct role in apoptosis, as we lack mechanistic information about their cellular 'apoptotic' substrates and the mechanisms by which they execute cell death. Here, we review reports describing a role for caspase-1 in macrophage apoptosis in response to infection by the bacteria Shigella and Salmonella, and a role for caspases-1 and -11 in neuronal apoptosis and neurodegeneration. We finally discuss the controversial role of caspase-12 in ER stress apoptosis (Figure 4).

Caspase-1 in macrophage apoptosis by Shigella and Salmonella. Shigella and Salmonella-infected macrophages undergo apoptosis. It has been postulated that the direct binding between caspase-1 and the bacterially secreted invasive proteins IpaB and SipB, respectively, results in the activation of caspase- 1 and leads to cell 


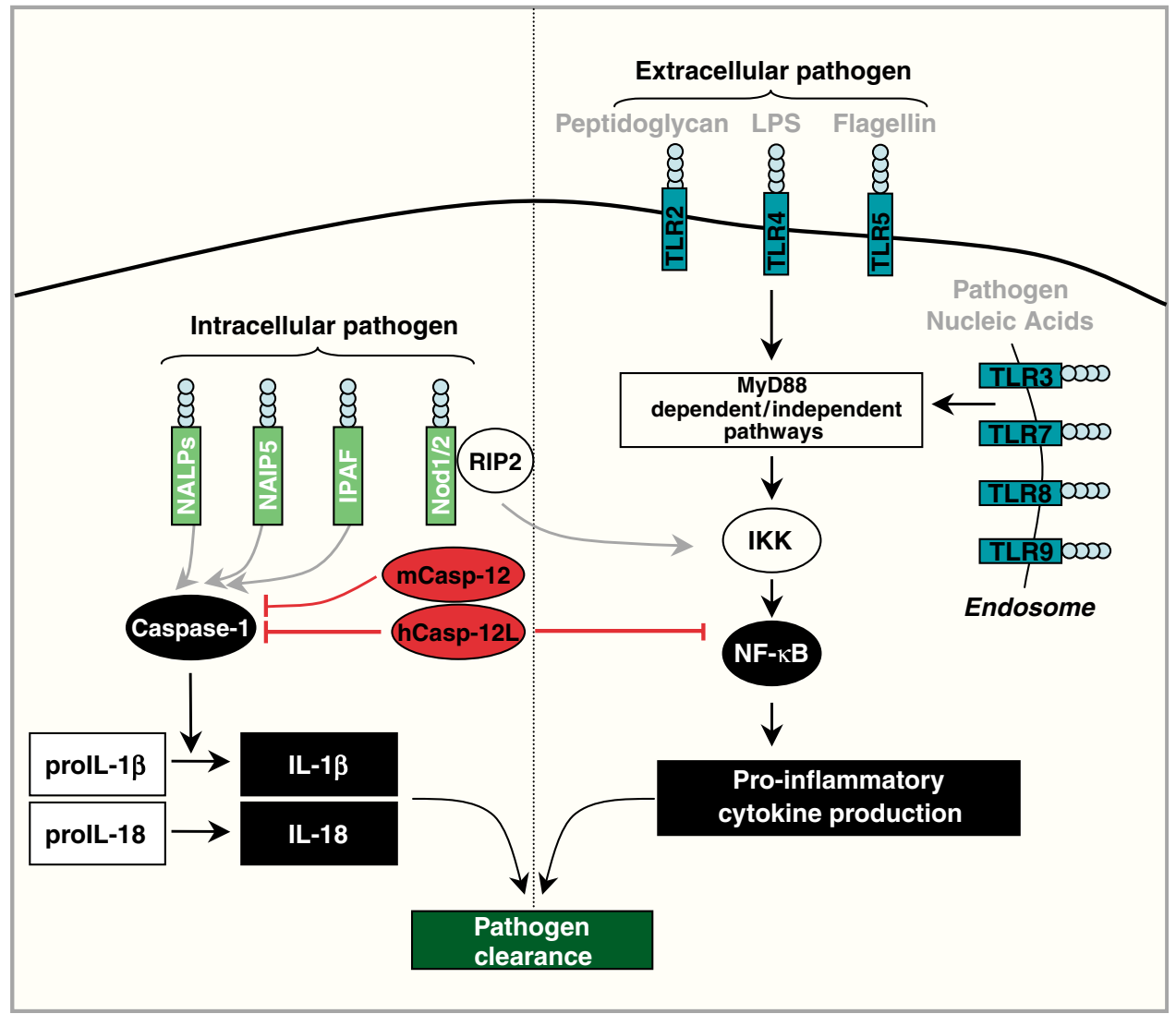

Figure 3 A model depicting the inflammatory pathways activated by extracellular and intracellular pathogens and the role of caspase-12 in modulating these pathways. The innate immune system possesses specific molecules which alert the host to pathogen infections. Extracellular pathogens commonly signal through Toll-like receptors (TLRs), leading to the eventual activation of NF- $\kappa$ B and induction of its target genes. In contrast, intracellular bacteria are commonly sensed through NOD-like receptors (NLRs), which lead to the activation of caspase- 1 and subsequently the processing of pro-IL- $1 \beta$ and pro-IL-18. The activity of both caspase-1 and NF- $\kappa$ B is necessary for pathogen clearance. Caspase- 12 is shown to down regulate the inflammatory response by directly inhibiting both caspase-1 and NF- $\kappa \mathrm{B}$ activation

death. ${ }^{63,64}$ This hypothesis has recently been re-examined and SipB binding per se was shown insufficient to activate the catalytic activity of caspase- 1 in the absence of flagellinexpressing bacteria. This led to the finding that caspase-1 activation involves IPAF-mediated sensing of the Salmonella flagellin, a process requiring SipB indirectly (Figure 4). ${ }^{31}$ In any event, it appears that caspase- 1 is indispensable in macrophage apoptosis induced by Shigella or Salmonella. Studies using caspase-1 selective inhibitors ${ }^{63-65}$ as well as caspase-1 deficient cells demonstrated the requirement for caspase-1 in macrophage apoptosis. ${ }^{64,66,67}$ However, the molecular mechanism linking caspase-1 activation to macrophage apoptosis remains unknown. It is noteworthy that caspases-2, -3 and -11 are not engaged following caspase-1 activation and that $\mathrm{Bcl}-2$ overexpression does not block Shigella-induced apoptosis in macrophages. ${ }^{66}$ Although caspase-1-mediated apoptosis has been widely considered as the main pathway leading to cell death by both Shigella and Salmonella, necrosis was also described. SipB overexpression in caspase-1-deficient macrophages was also shown to induce autophagic cell death. ${ }^{68}$

Caspases-1 and -11 in neuronal apoptosis and neurodegeneration. Early evidence that caspase- 1 plays a role in neuronal cell death came from the findings that caspase-1-deficient neurons showed prolonged survival following trophic factor withdrawal-induced apoptosis. ${ }^{69,70}$ Similarly, neuronal overexpression of a dominant negative and catalytically inactive $\left(\mathrm{C}^{285} \mathrm{G}\right)$ caspase-1 in mice resulted in an increase in resistance to neurotoxicity. ${ }^{71}$ So far, there does not appear to be a common event responsible for inducing caspase-1 activation in neurodegenerative diseases. Hypomorphic mutations in the gene encoding superoxide dismutase (SOD1) have been associated with ALS. $^{72}$ The resulting increase in oxidative stress in SOD1impaired mice is believed to stimulate caspase- 1 activation but through a presently unknown mechanism. Neuronal cell death is also common in experimental autoimmune encephalomyelitis (EAE). ${ }^{73}$ Caspase-1 mRNA levels positively correlate with the severity of $E A E$, and mice deficient in caspase-1, or treated with the broad spectrum caspase inhibitor zVAD-FMK, are less susceptible to EAE. ${ }^{73}$ It is conceivable that caspase-1 could initiate apoptosis directly by cleaving cellular proteins to dismantle the cell, or indirectly through maturation of $\mathrm{IL}-1 \beta$ and the activation of inflammatory pathways that feed back on neurons and induce their cell death. In agreement with this hypothesis, elevated levels of IL-1 $\beta$ have been found in brain biopsies or cerebrospinal fluid taken from patients suffering from brain injury, Parkinson's disease, Alzheimer's disease, epilepsy, 


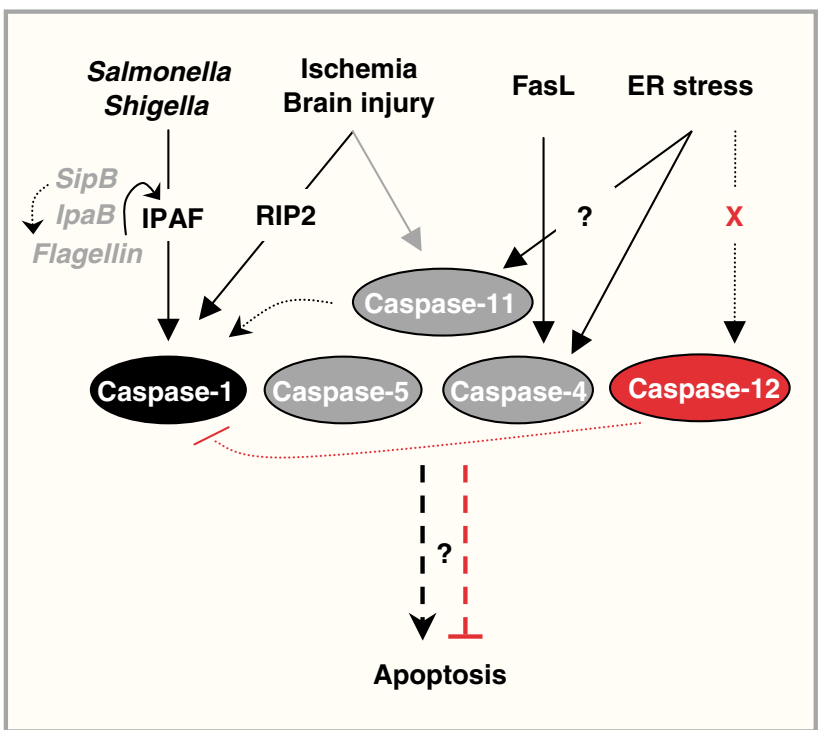

Figure 4 The role of the inflammatory caspases in apoptosis. Caspase- 1 is required for macrophage apoptosis induced by the bacteria Shigella and Salmonella. This seems to be mediated through activation of caspase-1 by a flagellin-induced IPAF inflammasome. Whether the direct binding between caspase- 1 and the bacteriallyderived proteins $\mathrm{SipB}$ and $\mathrm{IpaB}$ is required for caspase-1 activation is not clear. Caspases-1 and -11 appear to be essential in neurodegeneration. The CARD-containing kinase RIP2 is proposed to activate caspase-1 in neurons. Endoplasmic Reticulum (ER) stress induces apoptosis, however, the initiator caspase in this pathway remains elusive. Caspase- 4 seems to be required for cell death in response to this stress, while caspase-12 has been recently shown to be dispensable. We still do not know how the inflammatory caspases execute apoptosis: Whether this involves direct processing of cell 'survival' substrates by the inflammatory caspases, or through activation of the executioner caspases-3, -6 or -7 remains to be elucidated

MS and other neurological disorders. ${ }^{74}$ Additionally, IL-1Ra and IL-1 $\beta$ neutralizing antibodies were shown to block apoptosis induced by trophic factor withdrawal in animal models of ischemia. ${ }^{75}$ Similarly, caspase- 11 deficient mice display a marked decrease in striatum and hippocampus apoptosis following ischemic brain trauma. ${ }^{54}$ However, it remains unclear whether caspase-11 initiates apoptosis independently of caspase-1 or whether it acts by modulating caspase-1 activity (Figure 4 ). While caspase-11 was shown to be required for caspase- 1 activation, ${ }^{60}$ it was also reported to activate caspase-3 independently of caspase $-1 .{ }^{55}$ Whether caspases- 1 and -11 are activated by an 'inflammasome' in the central nervous system remains to be investigated. Interestingly, the CARD-containing kinase RIP2 and the CARD-only protein COP were shown in neuronal cells to regulate caspase- 1 activation and inhibition, respectively, suggesting that a macromolecular complex similar to the inflammasome might form in neurons. ${ }^{76}$

Caspase-12 and ER stress apoptosis: a controversial issue. In rodents, caspase-12 was initially proposed to play a role in mediating ER stress apoptosis as well as cell death in response to amyloid $\beta$ toxicity. ${ }^{77}$ More recently, multiple groups failed to reproduce these results showing that caspase-12 is dispensable for apoptosis initiated by ER stressors or other apoptotic stimuli including activators of the extrinsic or intrinsic cell death pathways. ${ }^{21,37,38,78}$ This controversy may exist for two main reasons. First, the levels of caspase-11 were not examined in the initial caspase-12-deficient mice. ${ }^{77}$ The difference in results could be explained if the mice described in $^{77}$ had altered expression levels of a second caspase required for ERstress apoptosis. Second, many of the studies reporting caspase-12 activation in response to ER stress relied on the observation of caspase-12 cleavage products on western blots as evidence for its activation. Most importantly, the catalytic activity of caspase-12 was never evaluated, and it remains unknown whether these cleavage products represent autocleavage or calpain cleavage events. Indeed, calpains have been reported to process caspase-12. ${ }^{79,80}$ The relevance of this processing remains to be understood. We have recently observed that rodent caspase- 12 is catalytically inefficient (manuscript in preparation) and have shown that its catalytic cysteine is dispensable for its effects in inflammation ${ }^{12}$ (see below). These results therefore suggest that caspase-12 may be incapable of efficiently processing cellular substrates and initiating apoptosis (Figure 4).

Conclusions. This past decade has seen significant advances in our understanding of the regulatory mechanisms of the inflammatory caspases. The finding that the 'inflammasome' is a highly specific mediator of caspase activation has begun to uncover the complexity of their regulation. In addition, the discovery of caspase-12 polymorphisms and the characterization of their role in sepsis and the host response to pathogenic infection has emphasized the essential role of the inflammatory caspases in innate immunity. Despite these recent advances, many questions remain to be answered. What determines the specificity of inflammasome assembly and activation? What are the advantages of caspase- 1 inhibition by caspase- 12 in individuals of African descent? Are there other caspase-1 substrates essential for its effects in innate immunity? Answering these questions will greatly improve our understanding of the inflammatory caspases, and may shed light on novel therapeutic targets for the treatment of sepsis and other infectious diseases.

1. Thomas L. Germs. N Engl J Med 1972; 287: 553-555.

2. Bone RC, Sprung CL, Sibbald WJ. Definitions for sepsis and organ failure. Crit Care Med 1992; 20: 724-726.

3. Levy MM, Fink MP, Marshall JC, Abraham E, Angus D, Cook D et al. 2001 SCCM/ESICM/ ACCP/ATS/SIS International Sepsis Definitions Conference. Intens Care Med 2003; 29: 530-538.

4. Riedemann NC, Guo RF, Ward PA. Novel strategies for the treatment of sepsis. Nat Med 2003; 9: 517-524.

5. Hotchkiss RS, Karl IE. The pathophysiology and treatment of sepsis. N Engl J Med 2003; 348: $138-150$.

6. Eskandari MK, Bolgos G, Miller C, Nguyen DT, DeForge LE, Remick DG. Anti-tumor necrosis factor antibody therapy fails to prevent lethality after cecal ligation and puncture or endotoxemia. J Immunol 1992; 148: 2724-2730.

7. Cohen J. Adjunctive therapy in sepsis: a critical analysis of the clinical trial programme. $\mathrm{Br}$ Med Bull 1999; 55: 212-225.

8. Docke WD, Randow F, Syrbe U, Krausch D, Asadullah K, Reinke P et al. Monocyte deactivation in septic patients: restoration by IFN-gamma treatment. Nat Med 1997; 3: $678-681$ 
9. Hotchkiss RS, Chang KC, Swanson PE, Tinsley KW, Hui JJ, Klender P et al. Caspase inhibitors improve survival in sepsis: a critical role of the lymphocyte. Nat Immunol 2000; 1 : 496-501.

10. Vincent $\mathrm{JL}$, Sun $\mathrm{Q}$, Dubois MJ. Clinical trials of immunomodulatory therapies in severe sepsis and septic shock. Clin Infect Dis 2002; 34: 1084-1093.

11. Saleh M, Vaillancourt JP, Graham RK, Huyck M, Srinivasula SM, Alnemri ES et al. Differential modulation of endotoxin responsiveness by human caspase-12 polymorphisms. Nature 2004; 429: 75-79.

12. Saleh MMJC, Wolinski MK, Bensinger SJ, Fitzgerald P, Droin N, Ulevitch RJ et al. Enhanced bacterial clearance and sepsis resistance in caspase-12 deficient mice. Nature 2006; 440: 1064-1068.

13. Hagberg L, Briles DE, Eden CS. Evidence for separate genetic defects in $\mathrm{C} 3 \mathrm{H} / \mathrm{HeJ}$ and $\mathrm{C} 3 \mathrm{HeB} / \mathrm{FeJ}$ mice, that affect susceptibility to gram-negative infections. J Immunol 1985 134: 4118-4122.

14. Martinon F, Tschopp J. Inflammatory caspases; linking an intracellular innate immune system to autoinflammatory diseases. Cell 2004; 117: 561-574.

15. Arbour NC, Lorenz E, Schutte BC, Zabner J, Kline JN, Jones M et al. TLR4 mutations are associated with endotoxin hyporesponsiveness in humans. Nat Genet 2000; 25: 187-191.

16. Lamkanfi M, Declercq W, Kalai M, Saelens X, Vandenabeele P. Alice in caspase land. A phylogenetic analysis of caspases from worm to man. Cell Death Differ 2002; 9: 358-361.

17. Watson RW, Rotstein OD, Parodo J, Bitar R, Marshall JC. The IL-1 beta-converting enzyme (caspase-1) inhibits apoptosis of inflammatory neutrophils through activation of IL1 beta. J Immunol 1998; 161: 957-962.

18. Lin $X Y$, Choi MS, Porter AG. Expression analysis of the human caspase-1 subfamily reveals specific regulation of the CASP5 gene by lipopolysaccharide and interferongamma. J Biol Chem 2000; 275: 39920-39926.

19. Chawla-Sarkar M, Lindner DJ, Liu YF, Williams BR, Sen GC, Silverman RH et al. Apoptosis and interferons: role of interferon-stimulated genes as mediators of apoptosis. Apoptosis 2003; 8: 237-249.

20. Fischer H, Koenig U, Eckhart L, Tschachler E. Human caspase 12 has acquired deleterious mutations. Biochem Biophys Res Commun 2002; 293: 722-726.

21. Kalai M, Lamkanfi M, Denecker G, Boogmans M, Lippens S, Meeus A et al. Regulation of the expression and processing of caspase-12. J Cell Biol 2003; 162: 457-467.

22. Kobori M, Yang Z, Gong D, Heissmeyer V, Zhu H, Jung YK et al. Wedelolactone suppresses LPS-induced caspase-11 expression by directly inhibiting the IKK complex. Cell Death Differ 2004; 11: 123-130.

23. Schauvliege R, Vanrobaeys J, Schotte $P$, Beyaert R. Caspase-11 gene expression in response to lipopolysaccharide and interferon-gamma requires nuclear factor-kappa $B$ and signal transducer and activator of transcription (STAT) 1. J Biol Chem 2002; 277: 4162441630.

24. Hur J, Kim SY, Kim H, Cha S, Lee MS, Suk K. Induction of caspase-11 by inflammatory stimuli in rat astrocytes: lipopolysaccharide induction through p38 mitogen-activated protein kinase pathway. FEBS Lett 2001; 507: 157-162.

25. Kuida K, Lippke JA, Ku G, Harding MW, Livingston DJ, Su MS et al. Altered cytokine export and apoptosis in mice deficient in interleukin-1 beta converting enzyme. Science 1995 267: 2000-2003

26. Li P, Allen H, Banerjee S, Franklin S, Herzog L, Johnston C et al. Mice deficient in IL-1 betaconverting enzyme are defective in production of mature IL-1 beta and resistant to endotoxic shock. Cell 1995; 80: 401-411.

27. Mariathasan S, Weiss DS, Newton K, McBride J, O'Rourke K, Roose-Girma M et al. Cryopyrin activates the inflammasome in response to toxins and ATP. Nature 2006; 440 228-232.

28. Kanneganti TD, Ozoren N, Body-Malapel M, Amer A, Park JH, Franchi L et al. Bacterial RNA and small antiviral compounds activate caspase-1 through cryopyrin/Nalp3. Nature 2006; 440: 233-236.

29. Martinon F, Petrilli V, Mayor A, Tardivel A, Tschopp J. Gout-associated uric acid crystals activate the NALP3 inflammasome. Nature 2006; 440: 237-241.

30. Franchi L, Amer A, Body-Malapel M, Kanneganti TD, Ozoren N, Jagirdar R et al. Cytosolic flagellin requires Ipaf for activation of caspase-1 and interleukin 1beta in salmonellainfected macrophages. Nat Immunol 2006; 7: 576-582.

31. Miao EA, Alpuche-Aranda CM, Dors M, Clark AE, Bader MW, Miller SI et al. Cytoplasmic flagellin activates caspase-1 and secretion of interleukin 1beta via Ipaf. Nat Immunol 2006; 7: $569-575$.

32. Ren T, Zamboni DS, Roy CR, Dietrich WF, Vance RE. Flagellin-deficient Legionella mutants evade caspase-1- and Naip5-mediated macrophage immunity. PLOS Pathog 2006; 2: e18.

33. Molofsky AB, Byrne BG, Whittield NN, Madigan CA, Fuse ET, Tateda K et al. Cytosolic recognition of flagellin by mouse macrophages restricts Legionella pneumophila infection. $J$ Exp Med 2006; 203: 1093-1104.

34. Tschopp J, Martinon F, Burns K. NALPs: a novel protein family involved in inflammation. Nat Rev Mol Cell Biol 2003; 4: 95-104.

35. Zamboni DS, Kobayashi KS, Kohlsdorf T, Ogura Y, Long EM, Vance RE et al. The Birc1e cytosolic pattern-recognition receptor contributes to the detection and control of Legionella pneumophila infection. Nat Immunol 2006; 7: 318-325

36. Martinon F, Burns K, Tschopp J. The inflammasome: a molecular platform triggering activation of inflammatory caspases and processing of prolL-beta. Mol Cell 2002; 10: 417426.
37. Hitomi J, Katayama T, Eguchi Y, Kudo T, Taniguchi M, Koyama $Y$ et al. Involvement of caspase-4 in endoplasmic reticulum stress-induced apoptosis and Abeta-induced cell death. J Cell Biol 2004; 165: 347-356.

38. Obeng EA, Boise LH. Caspase-12 and caspase- 4 are not required for caspase-dependent endoplasmic reticulum stress-induced apoptosis. J Biol Chem 2005; 280: 29578-29587.

39. Ray CA, Black RA, Kronheim SR, Greenstreet TA, Sleath PR, Salvesen GS et al. Vira inhibition of inflammation: cowpox virus encodes an inhibitor of the interleukin-1 beta converting enzyme. Cell 1992; 69: 597-604

40. Young JL, Sukhova GK, Foster D, Kisiel W, Libby P, Schonbeck U. The serpin proteinase inhibitor 9 is an endogenous inhibitor of interleukin 1beta-converting enzyme (caspase-1) activity in human vascular smooth muscle cells. J Exp Med 2000; 191: 1535-1544

41. Druilhe A, Srinivasula SM, Razmara M, Ahmad M, Alnemri ES. Regulation of IL-1beta generation by Pseudo-ICE and ICEBERG, two dominant negative caspase recruitment domain proteins. Cell Death Differ 2001; 8: 649-657.

42. Humke EW, Shriver SK, Starovasnik MA, Fairbrother WJ, Dixit VM. ICEBERG: a novel inhibitor of interleukin-1beta generation. Cell 2000; 103: 99-111.

43. Lee J, Hur J, Lee P, Kim JY, Cho N, Kim SY et al. Dual role of inflammatory stimuli in activation-induced cell death of mouse microglial cells. Initiation of two separate apoptotic pathways via induction of interferon regulatory factor-1 and caspase-11. J Biol Chem 2001 276: 32956-32965.

44. Cerretti DP, Kozlosky CJ, Mosley B, Nelson N, Van Ness K, Greenstreet TA et al. Molecular cloning of the interleukin-1 beta converting enzyme. Science 1992; 256: 97-100.

45. Ghayur T, Banerjee S, Hugunin M, Butler D, Herzog L, Carter A et al. Caspase- 1 processes IFN-gamma-inducing factor and regulates LPS-induced IFN-gamma production. Nature 1997; 386: 619-623.

46. Kumar S, Hanning CR, Brigham-Burke MR, Rieman DJ, Lehr R, Khandekar S et al. Interleukin-1F7B (IL-1H4/IL-1F7) is processed by caspase-1 and mature IL-1F7B binds to the IL-18 receptor but does not induce IFN-gamma production. Cytokine 2002; 18: 61-71.

47. Schmitz J, Owyang A, Oldham E, Song Y, Murphy E, McClanahan TK et al. IL-33, an interleukin-1-like cytokine that signals via the IL-1 receptor-related protein ST2 and induces T helper type 2-associated cytokines. Immunity 2005; 23: 479-490.

48. Kayalar C, Ord T, Testa MP, Zhong LT, Bredesen DE. Cleavage of actin by interleukin 1 beta-converting enzyme to reverse DNase I inhibition. Proc Natl Acad Sci USA 1996; 93 2234-2238.

49. Beyaert R, Kidd VJ, Cornelis S, Van de Craen M, Denecker G, Lahti JM et al. Cleavage of PITSLRE kinases by ICE/CASP-1 and CPP32/CASP-3 during apoptosis induced by tumor necrosis factor. J Biol Chem 1997; 272: 11694-11697.

50. Kahns S, Kalai M, Jakobsen LD, Clark BF, Vandenabeele P, Jensen PH. Caspase-1 and caspase-8 cleave and inactivate cellular parkin. J Biol Chem 2003; 278: 23376-23380.

51. Kamada S, Washida M, Hasegawa J, Kusano H, Funahashi Y, Tsujimoto Y. Involvement of caspase-4(-like) protease in Fas-mediated apoptotic pathway. Oncogene 1997; 15: 285 290.

52. Schwartz Jr S, Yamamoto H, Navarro M, Maestro M, Reventos J, Perucho M. Frameshift mutations at mononucleotide repeats in caspase- 5 and other target genes in endometrial and gastrointestinal cancer of the microsatellite mutator phenotype. Cancer Res 1999; 59 : 2995-3002.

53. Krippner-Heidenreich A, Talanian RV, Sekul R, Kraft R, Thole $\mathrm{H}$, Ottleben $\mathrm{H}$ et al. Targeting of the transcription factor Max during apoptosis: phosphorylation-regulated cleavage by caspase-5 at an unusual glutamic acid residue in position P1. Biochem J 2001 358: 705-715.

54. Kang SJ, Wang S, Hara H, Peterson EP, Namura S, Amin-Hanjani S et al. Dual role of caspase-11 in mediating activation of caspase- 1 and caspase- 3 under pathological conditions. J Cell Biol 2000; 149: 613-622.

55. Kang SJ, Wang S, Kuida K, Yuan J. Distinct downstream pathways of caspase-11 in regulating apoptosis and cytokine maturation during septic shock response. Cell Death Differ 2002; 9: 1115-1125.

56. Joshi VD, Kalvakolanu DV, Hebel JR, Hasday JD, Cross AS. Role of caspase 1 in murine antibacterial host defenses and lethal endotoxemia. Infect Immun 2002; 70: 6896-6903.

57. Tsuji NM, Tsutsui H, Seki E, Kuida K, Okamura H, Nakanishi K et al. Roles of caspase-1 in Listeria infection in mice. Int Immunol 2004; 16: 335-343.

58. Mariathasan S, Weiss DS, Dixit VM, Monack DM. Innate immunity against Francisella tularensis is dependent on the ASC/caspase-1 axis. J Exp Med 2005; 202: 1043-1049.

59. Lara-Tejero M, Sutterwala FS, Ogura Y, Grant EP, Bertin J, Coyle AJ et al. Role of the caspase-1 inflammasome in Salmonella typhimurium pathogenesis. J Exp Med 2006; 203 1407-1412.

60. Wang S, Miura M, Jung YK, Zhu H, Li E, Yuan J. Murine caspase-11, an ICE-interacting protease, is essential for the activation of ICE. Cell 1998; 92: 501-509.

61. Mueller NJ, Wilkinson RA, Fishman JA. Listeria monocytogenes infection in caspase-11 deficient mice. Infect Immun 2002; 70: 2657-2664.

62. Xue Y, Daly A, Yngvadottir B, Liu M, Coop G, Kim Y et al. Spread of an inactive form of caspase-12 in humans is due to recent positive selection. Am J Hum Genet 2006; 78: 659670.

63. Chen Y, Smith MR, Thirumalai K, Zychlinsky A. A bacterial invasin induces macrophage apoptosis by binding directly to ICE. EMBO J 1996; 15: 3853-3860.

64. Hersh D, Monack DM, Smith MR, Ghori N, Falkow S, Zychlinsky A. The Salmonella invasin SipB induces macrophage apoptosis by binding to caspase-1. Proc Natl Acad Sci USA 1999; 96: 2396-2401. 
65. Hilbi $\mathrm{H}$, Chen $\mathrm{Y}$, Thirumalai $\mathrm{K}$, Zychlinsky A. The interleukin 1beta-converting enzyme, caspase 1 , is activated during Shigella flexneri-induced apoptosis in human monocyte derived macrophages. Infect Immun 1997; 65: 5165-5170.

66. Hilbi H, Moss JE, Hersh D, Chen Y, Arondel J, Banerjee $S$ et al. Shigella-induced apoptosis is dependent on caspase-1 which binds to IpaB. J Biol Chem 1998; 273: 3289532900

67. van der Velden AW, Velasquez M, Starnbach MN. Salmonella rapidly kill dendritic cells via a caspase-1-dependent mechanism. J Immunol 2003; 171: 6742-6749.

68. Hernandez LD, Pypaert M, Flavell RA, Galan JE. A Salmonella protein causes macrophage cell death by inducing autophagy. J Cell Biol 2003; 163: 1123-1131.

69. Friedlander RM, Gagliardini V, Hara H, Fink KB, Li W, MacDonald G et al. Expression of a dominant negative mutant of interleukin-1 beta converting enzyme in transgenic mice prevents neuronal cell death induced by trophic factor withdrawal and ischemic brain injury. J Exp Med 1997; 185: 933-940.

70. Schielke GP, Yang GY, Shivers BD, Betz AL. Reduced ischemic brain injury in interleukin-1 beta converting enzyme-deficient mice. J Cereb Blood Flow Metab 1998; 18: 180-185.

71. Klevenyi P, Andreassen O, Ferrante RJ, Schleicher Jr JR, Friedlander RM, Beal MF. Transgenic mice expressing a dominant negative mutant interleukin-1beta converting enzyme show resistance to MPTP neurotoxicity. Neuroreport 1999; 10: 635-638.

72. Rosen DR. Mutations in $\mathrm{Cu} / \mathrm{Zn}$ superoxide dismutase gene are associated with familial amyotrophic lateral sclerosis. Nature 1993; 364: 362.
73. Furlan R, Martino G, Galbiati F, Poliani PL, Smiroldo S, Bergami A et al. Caspase-1 regulates the inflammatory process leading to autoimmune demyelination. $J$ Immunol 1999; 163: 2403-2409.

74. Hopkins SJ, Rothwell NJ. Cytokines and the nervous system. I: Expression and recognition. Trends Neurosci 1995; 18: 83-88.

75. Friedlander RM, Gagliardini V, Rotello RJ, Yuan J. Functional role of interleukin 1 beta (IL-1 beta) in IL-1 beta-converting enzyme-mediated apoptosis. J Exp Med 1996; 184: 717-724.

76. Wang X, Wang H, Figueroa BE, Zhang WH, Huo C, Guan Y et al. Dysregulation of receptor interacting protein-2 and caspase recruitment domain only protein mediates aberrant caspase-1 activation in Huntington's disease. J Neurosci 2005; 25: 11645-11654.

77. Nakagawa T, Zhu H, Morishima N, Li E, Xu J, Yankner BA et al. Caspase-12 mediates endoplasmic-reticulum-specific apoptosis and cytotoxicity by amyloid-beta. Nature 2000; 403: $98-103$

78. Di Sano F, Ferraro E, Tufi R, Achsel T, Piacentini M, Cecconi F. Endoplasmic reticulum stress induces apoptosis by an apoptosome-dependent but caspase 12-independent mechanism. J Biol Chem 2006; 281: 2693-2700.

79. Nakagawa T, Yuan J. Cross-talk between two cysteine protease families. Activation of caspase-12 by calpain in apoptosis. J Cell Biol 2000; 150: 887-894.

80. Tan Y, Dourdin N, Wu C, De Veyra T, Elce JS, Greer PA. Ubiquitous calpains promote caspase-12 and Jnk activation during ER stress-induced apoptosis. J Biol Chem 2006; 281: 16016-16024. 